\title{
EMPREENDEDORISMO: UMA ANÁLISE DOS FATORES A SEREM CONSIDERADOS NO DESENVOLVIMENTO DE NOVOS NEGÓCIOS
}

\author{
ENTREPRENEURSHIP: AN ANALYSIS OF THE FACTORS TO BE \\ CONSIDERED IN THE DEVELOPMENT OF NEW BUSINESSES
}

\author{
Recebido: 29/09/2016 - Aprovado: 04/01/2017 - Publicado: 27/062017 \\ Processo de Avaliação: Double Blind Review
}

\author{
Cláudio José Carvajal Júnior ${ }^{1}$ \\ Doutor em Engenharia Biomédica \\ Universidade Mogi das Cruzes-UMC \\ prof.claudiocarvajal@gmail.com \\ Luiz Teruo Kawamoto Júnior \\ Doutor em Engenharia Biomédica \\ Universidade Mogi das Cruzes-UMC \\ luiztk@umc.br
}

\begin{abstract}
RESUMO: A criação de novos negócios é um desafio para empresas e pessoas que se aventuram em um cenário econômico-social intensamente mutável. $\mathrm{O}$ empreendedorismo requer estudo e preparo prévio para aumentar as chances de sucesso do projeto. O presente artigo tem por objetivo analisar alguns fatores importantes para viabilizar novos projetos de negócios, considerando o perfil do empreendedor e as etapas de elaboração de um bom plano de negócios. Neste estudo de abordagem qualitativa, os dados coletados foram selecionados por meio de um levantamento bibliográfico. Dentre os fatores identificados nessa análise teórica temos: O bom planejamento prévio do negócio é fator indispensável para o seu sucesso. Assim, é preciso criar uma cultura organizacional favorável ao desenvolvimento da empresa, que propicie um bom clima organizacional para estimular o trabalho em equipe, a criatividade e a inovação, como fatores indispensáveis para competitividade no mundo dos negócios.
\end{abstract}

Palavras-chave: Empreendedorismo; Liderança, criação de novos negócios; Plano de negócios.

\footnotetext{
${ }^{1}$ Autor para correspondência: Universidade Mogi das Cruzes- Av. Dr. Cândido Xavier de Almeida e Souza, 200 Mogi das Cruzes- SP - Brasil- CEP 08780-911.
}

REMIPE- Revista de Micro e Pequenas Empresas e Empreendedorismo da Fatec Osasco V. 3, N¹, jan.-jun. 2017. 
ABSTRACT: The creation of new business is a challenge for enterprises and persons who dare in intensely changeable social-economical scenery. The development of enterprises applies for study and prior preparation to increase the chances of success of the project. The present article has the objective to analyze some important factors make possible the development of business projects, considering the profile of the entrepreneur and the stages of the preparation of a good plan of business. The good prior projection of the business is an essential factor for his success. It is necessary to create a culture of organizations favorable to the development of the enterprise. The good climate of organizations stimulates the work in team, the creativity and the innovation, essential factors for competitiveness in the world of the business.

Key-words: Development of Enterprises, leadership, creation of new business, business plan.

\section{INTRODUÇÃO}

O empreendedorismo é uma atividade crescente no Brasil. Segundo o Relatório Executivo do Global Entrepreneurship Monitor (GEM, 2013) a taxa de empreendedores no Brasil, referente à população de 18 a 64 anos foi de 32,3\%, o que representa um crescimento de 5,4\% em relação a 2011 (26,9\%), e de 11,4\% em relação a 2002 (20,9\%). Ainda, de acordo com esse relatório, abrir o próprio negócio ocupa o terceiro lugar na lista de sonhos dos brasileiros, enquanto fazer carreira em uma empresa aparece em oitavo lugar. Por esse motivo, o presente artigo tem por objetivo realizar um levantamento bibliográfico e posterior análise dos dados, para identificar na literatura fatores que possam contribuir para a melhoria dos resultados dos investimentos do empreendedor brasileiro. Este estudo foi elaborado com uma abordagem qualitativa, sendo que os dados coletados foram selecionados por meio de um levantamento bibliográfico.

Segundo pesquisa realizada pelo Serviço Brasileiro de Apoio à Micro e Pequena Empresa - Sebrae - 50\% (metade) das empresas brasileiras encerram suas atividades com até dois anos de existência, 56,4\% com até três anos de existência e 60\% (a maioria) com até quatro anos de existência. Logo, abrir seu próprio negócio no Brasil é bastante arriscado. Por outro lado, cerca de 470 mil novas empresas são abertas por ano no país. Apesar do alto risco e das dificuldades, o brasileiro continua sendo um povo com perfil empreendedor.

É comum asa pessoas afirmarem que o mundo está mudando nos cenários político, econômico e social. Os países formam blocos, derrubando fronteiras comerciais e impondo um novo tipo de relacionamento de mercado. A gestão e a tecnologia da informação agregam inovações que têm impacto direto na vida das pessoas. Quem está REMIPE- Revista de Micro e Pequenas Empresas e Empreendedorismo da Fatec Osasco V. 3, N¹, jan.-jun. 2017. 
liderando estas mudanças são indivíduos ou equipes com características diferenciadas. São visionários que questionam, arriscam, querem algo diferente, fazem acontecer. São empreendedores (DOLABELA, 2008).

Os empreendedores são pessoas diferenciadas, que possuem motivação singular. São apaixonados pelo que fazem, não se contentam em ser mais um na multidão, querem deixar algo para sociedade e assim estão revolucionando o mundo. O momento atual pode ser chamado de "Era do Empreendedorismo", pois são os empreendedores que estão quebrando as barreiras sociais e culturais, renovando conceitos econômicos, quebrando paradigmas e gerando riquezas para a nova sociedade em que vivemos. O processo criativo do empreendedor gera novos contextos e promove o desenvolvimento dos novos negócios. O sonho do empreendedor é transformado em realidade por meio através de trabalho árduo, dedicação e perseverança. $\mathrm{O}$ empreendedor é marcado pela coragem, $\mathrm{o}$ que não significa que o medo não exista para ele. Significa que o medo é sobrepujado pela ação de seguir a visão. A visão pode surgir de uma necessidade ou de um despertar para algo novo.

O sucesso do empreendedor está fundamentado em três pontos básicos: (1) o desafio que estimula as pessoas a lutarem por alguma coisa; (2) o resultado que dá a sensação de vitória e autoconfiança para continuar adiante e (3) a própria responsabilidade de comemorar as vitórias e corrigir os erros cometidos (DORNELAS, 2012).

Segundo as conclusões da referida pesquisa, pode-se deve-se ensinar empreendedorismo. Para isso, é preciso aumentar a conscientização dos educadores para o tema e fornecer ferramentas para identificar e valorizar oportunidades de novos negócios. É preciso desenvolver habilidades empreendedoras, capacidade de liderança e formas autônomas de pensar e gerir a vida profissional (CAPUCHA, 2007).

\section{PERFIL EMPREENDEDOR}

Estudos e pesquisas sobre comportamento e a personalidade do empreendedor fundamentam-se na ideia que o sucesso do empreendedor. Em 1961, David McClelland identificou dez das principais características de pessoas bem-sucedidas nos negócios em vários países e classificou as em forma de competência que o empreendedor deve ter, conforme demonstrado no quadro 1 :

REMIPE- Revista de Micro e Pequenas Empresas e Empreendedorismo da Fatec Osasco 
Quadro 1. Competências do empreendedor.

$\begin{array}{lll}\text { Realização } & \text { Planejamento } & \text { Poder } \\ \begin{array}{l}\text { Busca de Oportunidade e } \\ \text { Iniciativa }\end{array} & \text { Busca de Informações } & \text { Persuasão } \\ \begin{array}{l}\text { Correr Riscos Calculados } \\ \text { Exigência da Qualidade e } \\ \text { Eficiência }\end{array} & \begin{array}{l}\text { Estabelecimento de Metas } \\ \text { Planejamento }\end{array} & \begin{array}{l}\text { Redes de Contatos } \\ \text { Independência }\end{array} \\ \begin{array}{l}\text { Persistência e } \\ \text { Comprometimento }\end{array} & \text { Monitoramento Sistemático } & \text { Autoconfiança } \\ & & \end{array}$

Fonte: O Autor. - Baseado em David McCelland (1961).

Outro estudo realizado, sob um enfoque psicanalítico, Zalenazik \& Vries, (2006) percebem os empreendedores como pessoas influenciadas por uma infância turbulenta, marcadas por temas reais ou imaginários de pobreza, depravação, morte significativa e solidão. Esse estudo concluiu que os empreendedores são marcados por sentimentos persistentes de insatisfação, rejeição, impotência, derivados de conflitos relacionados com os pais.

Peter Drucker (2008) identificou as características comuns aos empreendedores bem sucedidos e construiu lista de características apresentada no quadro 2 :

Quadro 2. - Características do empreendedor.

1. Total comprometimento, determinação e perseverança;
2. Guiados pela autorrealização e crescimento;
3. Senso de oportunidade e orientação por metas;
4. Iniciativas por responsabilidades pessoais;
5. Persistência na resolução de problemas;
6. Conscientização e senso de humor;
7. Busca de "feedback";
8. Controle racional dos impulsos;
9. Tolerância ao stress, ambiguidade e incerteza;
10. Riscos moderados;
11. Pouca necessidade de status e poder;
12. Integridade e confiabilidade;
13. Decisão, urgência e paciência;
14. Lidar bem com o fracasso;
15. Formador de equipes.

Fonte: O Autor - Baseado em Peter Drucker (2008).

REMIPE- Revista de Micro e Pequenas Empresas e Empreendedorismo da Fatec Osasco 
Enfim, conforme Dornelas (2012), ao invés de focar os atributos de personalidade, é necessário analisar as habilidades e competências necessárias para o sucesso do empreendedor. Isto sim pode ser desenvolvido e adquirido ao longo da carreira dos novos empreendedores, de forma a ajudá-los a serem bem sucedidos.

\section{ESCOLHENDO O RAMO DE ATIVIDADE.}

Basicamente, existem três tipos de ramos de atividade, empresa industrial, empresa comercial e empresa de serviços, conforme Corrêa (2010):

Empresas industriais: São aquelas que transformam matérias-primas, manualmente ou com auxílio de máquinas e ferramentas, fabricando mercadorias. Abrangem desde o artesanato até a moderna produção de instrumentos eletrônicos.

Exemplos: fábrica de móveis artesanais, fábrica de roupas, fábrica de computadores, etc.

Conforme o GEM (2015), com o crescimento da área de tecnologia da informação e das comunicações nas últimas duas décadas, desde 1990 até agora, e as tendências de desenvolvimento de novas tecnologias nessa área, surgem ainda grandes oportunidades na área de negócios digitais, em todos os setores, como saúde, educação, indústria, serviços etc.

Segundo o SEBRAE (2013), dessa forma, há inúmeras oportunidades de negócios na utilização de novas tecnologias para o desenvolvimento de soluções para problemas das empresas e das pessoas. Podemos citar as plataformas que oferecem serviços de redes sociais, e-mails, sites de busca, e aplicativos que oferecem desde o entretenimento até intermediação de serviços de transporte urbano. São as chamadas startups de base tecnológica, empresas criadas com base em ideias de negócios inovadores, que tem grande potencial de crescimento num curto espaço de tempo.

Para Longhi (2011), startups são pequenas empresas criadas em casa ou em faculdades e que recebem pequenos aportes de capital, as quais exploram, normalmente, áreas inovadoras de algum setor do mercado, sendo o mais comum o setor de tecnologia, podendo sofrer um grande crescimento em um curto período de tempo. Para Hermanson (2011), startups são aquelas empresas de pequeno porte recém criadas, que possuem REMIPE- Revista de Micro e Pequenas Empresas e Empreendedorismo da Fatec Osasco 
atividades relacionadas a ideias inovadoras e criativas, visando baixos custos de manutenção e com o intuito de que essa ideia possibilite lucros altíssimos em um curto prazo.

A partir de uma análise das definições dos autores sobre startups observa-se que este tipo de empresa se apoia na incerteza, e por isso foi desenvolvido por Osterwalder (2011) um modelo de negócio denominado como Business Model Generatiion Canvas, o qual funciona como uma ferramenta de gerenciamento estratégico que permite desenvolver e fazer esboços de modelos de negócios novos ou existentes. Osterwalder (2011) alega que o modelo Canvas é um mapa das principais áreas que constituem uma empresa. Atualmente este modelo é um dos mais utilizados pelas startups como modelo de negócio, isso devido a ser um modelo de fácil aplicação e algo menos formal, podendo ser utilizado com mais frequência no dia a dia da empresa.

\section{COMPETITIVIDADE EMPRESARIAL}

Kaplan e Norton (2004) destacam que toda empresa enfrenta o desafio de obter sucesso em um ambiente de mercado extremamente competitivo. Complementam, ainda, que para sobreviver e crescer neste ambiente, ela precisa desenvolver sua competitividade empresarial. E como saber se a empresa é competitiva? É importante estabelecer metas que sejam mensuráveis para a empresa, e periodicamente avaliar se a empresa está atingindo e superando as metas definidas através de indicadores.

Os autores destacam, ainda, que existe uma grande gama de indicadores de produtividade e competitividade, como faturamento bruto, relação faturamento/número de empregados e relação faturamento/área ocupada. São indicadores financeiros, nãofinanceiros, setoriais, regionais, entre vários outros. Porém, é necessário identificar os que mais se apliquem ao seu negócio, como ferramentas de análise e avaliação.

Alta qualidade, bom serviço, inovação e preço são certamente os fatores-chave para o sucesso num ambiente competitivo. No entanto, esses atributos são quase commodities. Sem eles, a empresa está fadada ao fracasso. Com eles, a empresa entra no caminho do sucesso.

Corrêa (2010) afirma que as companhias precisam aprender novas formas de concorrer, que incluam capacidade para desenvolver produtos e fornecê-los mais rapidamente, para ter um produto com melhor projeto e estilo, para aumentar a oferta de mais vantagens, para construir um relacionamento mutuamente vantajoso com o cliente REMIPE- Revista de Micro e Pequenas Empresas e Empreendedorismo da Fatec Osasco 
no longo prazo e assim por diante. Cabe, porém, a cada empresa encontrar o seu "mix" de estratégias e definir os melhores caminhos para o sucesso.

\subsection{RECURSOS FINANCEIROS NECESSÁRIOS}

Silva (2013), afirma que o empreendedor deve orçar o montante de recursos necessários para a implantação do negócio. Toda a infraestrutura física do projeto (aquisição do ponto, máquinas, equipamentos e instalações, móveis e utensílios etc.); capital de giro - todos os recursos necessários ao financiamento do ciclo operacional da empresa, ou seja, aquisição de mercadorias, matéria-prima, financiamento a clientes etc. $\mathrm{O}$ autor destaca a necessidade de dispor de dinheiro em caixa ou em banco. As vendas à vista, aumento de prazos para pagamentos aos fornecedores, redução de estoques em níveis aceitáveis, maior rotação de estoques etc., diminuem a necessidade de capital de giro. Faturamento - Ao projetar as quantidades para vendas de produtos ou serviços, você deve multiplicá-las pelo preço de venda. A projeção do faturamento deve ser resultante do potencial de mercado, da capacidade produtiva e da força de vendas da empresa.

\subsection{MERCADO}

Para Kotler (2012), é importante considerar também se os produtos/serviços estão sujeitos a oscilações sazonais, ou seja, sofrem quedas ou aumento da demanda devido à mudança nas estações do ano, que influenciam nas preferências dos clientes (sorvetes vendem mais no verão) ou às limitações dos fornecedores (períodos de safra dos produtos agrícolas). No início das operações, é sempre aconselhável que a expectativa de vendas seja moderada, pois a empresa necessita de tempo para adquirir experiência e tornar seus produtos ou serviços conhecidos no mercado. 


\subsection{CUSTOS E FORMAÇÃO DE PREÇOS}

Segundo Dornelas (2005), estabelecer preços de venda competitivos é uma tarefa que exige do empresário o conhecimento dos componentes que dão origem ao preço de venda.

A definição da estrutura de custos é parcela importante neste processo, uma vez que possibilitará ao administrador saber quanto lucrou.

Muitas empresas não apuram seus custos e despesas de maneira precisa e os preços de venda são obtidos empiricamente. Essa prática influencia na transparência dos custos e no lucro da empresa, acarretando diversos problemas, tais como: preço de venda abaixo do real, o que diminui os lucros da empresa; preço de venda acima do real, o que dificulta as vendas; fabricação de produtos que dão pouco lucro em detrimento de outros mais rentáveis, ocasionando má alocação dos recursos; esforço de venda não orientado para produtos mais lucrativos; dificuldades para identificar e fixar ações para redução de custos e despesas, o que poderá levar a empresa a operar com custos e despesas mais altos do que deveria.

Como consequência de um ou mais desses problemas, a empresa terá um lucro e uma rentabilidade menor, constituindo-se numa ameaça ao seu crescimento e até à sua própria estabilidade econômico-financeira.

Para auxiliar o empresário na determinação dos preços de seus produtos, veja abaixo um roteiro básico de cálculo na empresa prestadora de serviços, que deverá ser preenchida com a ajuda de seu contador.

Dornelas (2012), afirma, ainda, que é preciso ter em mente que numa economia de mercado, quem define o preço de venda é o mercado.

\subsection{FOCO NO CLIENTE}

Silva (2013) afirma que o cliente é uma força indispensável para a futura empresa. Ele é o alvo dos produtos e serviços e deverá sentir-se plenamente atendido, maravilhado, encantado, surpreso. Entender que o preço a ser pago é justo e que os produtos e serviços correspondem à qualidade por ele esperada é o básico.

As pessoas quando procuram por produtos e serviços, geralmente, fazem comparação imediata, muitas vezes sem perceber: Qualidade percebida versus preço do REMIPE- Revista de Micro e Pequenas Empresas e Empreendedorismo da Fatec Osasco 
produto ou serviço. A qualidade percebida é um conjunto de características do produto ou serviço, que engloba aspectos intangíveis de difícil mensuração. A marca, por exemplo, é uma dessas características de valor agregado singular. Muitas vezes um produto de marca reconhecida tem um valor percebido pelo cliente muito maior do que outros produtos similares.

Kotler (2012), ao planejar a empresa é preciso esclarecer quem serão os clientes e o que eles esperam. Os produtos e serviços devem ser direcionados corretamente ao seu público. Portanto, é necessário se preocupar com a diferença que o produto e/ou serviço irá fazer para esses futuros clientes.

\subsection{LOCALIZAÇÃO E ESTRUTURA}

Dornelas (2012) destaca que para definir a localização da unidade de negócio, o empreendedor deve basear-se em dados concretos. Deve-se concentrar seus esforços na pesquisa de informações sobre os clientes, fornecedores, concorrentes, infraestrutura e logística. Essa pesquisa pode ser realizada pelo próprio empresário ou por profissionais especializados em pesquisa mercadológica.

A escolha do ponto ideal requer conhecimento de mercado, pois não dá para se guiar apenas pela intuição. O melhor é seguir critérios científicos.

Trata-se de uma importante etapa de todo o negócio, que deve levar em conta princípios estatísticos, como análise do fluxo de pedestres e veículos, hábitos de compra e poder aquisitivo dos consumidores. As dúvidas dos empreendedores aumentam em proporção ao número de opções e diminuem quando se têm objetivos bem definidos.

\subsection{EQUIPE}

Colaboradores são as pessoas que constituem e trabalham na empresa. Durante a fase de planejamento é preciso pensar no perfil dessas pessoas, no tipo de relacionamento que a empresa manterá com elas, bem como quais as relações referentes à legislação trabalhista aplicadas aos colaboradores.

Em face do contexto ora vivenciado pelas organizações, caracterizado por mudanças constantes de natureza econômica, social e tecnológica, torna-se fundamental, em qualquer empresa, uma administração voltada para a gestão de recursos humanos, REMIPE- Revista de Micro e Pequenas Empresas e Empreendedorismo da Fatec Osasco 
visto que a continuidade de sua existência será determinada pela qualidade agregada aos seus produtos ou serviços, tendo como base pessoas motivadas e com alto nível de qualidade pessoal e profissional.

A grande maioria dos especialistas em gestão de recursos humanos concorda que o diferencial hoje é o talento humano. Elevados índices de rotatividade, de absenteísmo, acidentes de trabalho, problemas com qualidade dos produtos, retrabalho, desperdício de materiais, baixos salários, condições de trabalho inadequadas e relações de trabalho insatisfatórias são fatores que estão diretamente relacionados à administração de recursos humanos, que, na maioria das empresas, é limitada ao cumprimento, apenas, dos aspectos legais da relação governo, empresa e empregado.

Drucker (2008) considera que para superar essas dificuldades, as empresas estão investindo em treinamentos que levem as pessoas ao conhecimento e desenvolvimento profissional, buscando uma maior capacidade de trabalho em equipe, bem como estão adaptando os móveis e as condições das áreas de trabalho visando o conforto e bem-estar de seus funcionários.

\section{DESENVOLVENDO A CULTURA EMPREENDEDORA EMPRESARIAL}

A cultura organizacional é composta por uma série de características do ambiente de trabalho, percebidas pelos empregados. A cultura compõe uma das forças importantes que influenciam o comportamento das pessoas. Compreende, além das políticas e normas formais, regras não formais, mas que são condicionadas às atitudes das pessoas da organização. A cultura impacta no processo de mudança, exigindo cuidado e tempo. Para que os gestores formulem políticas de mudança no processo organizacional e tenham sucesso é necessário, inicialmente, que os gestores compreendam a cultura e considerem seu impacto no planejamento da mudança que será implementada. Portanto, é indispensável, no desenvolvimento do ambiente de trabalho, os gerentes não só laurearem os empregados de excepcional rendimento, mas, também, possam servir de estimulo aos menos dedicados.

O entendimento de quatro pressupostos sobre a cultura da organização, é um ponto básico para o sucesso do diagnostico organizacional, geralmente naquelas intervenções onde se torna fundamental compreender como a organização funciona ao ponto de vista do comportamento humano. Os pressupostos são:

REMIPE- Revista de Micro e Pequenas Empresas e Empreendedorismo da Fatec Osasco V. 3, N¹, jan.-jun. 2017. 
Poder: Quem tem poder na organização? Até que ponto esse poder é distribuído? Qual o grau de centralização ou descentralização da autoridade? Quem determina as recompensas?

A empresa garante sua continuidade cumprindo sua missão com eficácia empresarial, envolvendo as questões de curto prazo (produção, eficiência e satisfação) e de longo prazo (capacidade de adaptar-se às mudanças e desenvolvimento contínuo).

As habilidades e competências dos gestores devem assegurar com que a empresa gere resultados suficientes para que se mantenha no mercado e cresça de forma contínua. Logo, o sucesso e a continuidade de qualquer empresa dependem dos resultados positivos (lucro) desejáveis e no que as atividades operacionais poderão gerar. Portanto, as empresas devem buscar crescer e serem competitivas.

Independentemente do tamanho da empresa é necessário estabelecer metas, parâmetros e estratégias. É importante ter um guia, um plano, que direcione as ações do presente como meio de atingir as metas traçadas para o futuro.

Drucker (2008) destaca que, além disso, o planejamento da empresa requer organização, controles, ferramentas para tomada de decisão e correção de rumos. Portanto, planeje e organize a sua empresa .

Outro ponto importante para o sucesso no mundo dos negócios, é criar uma cultura onde todos os funcionários também possam ser empreendedores dentro da sua empresa. O chamado intraempreendedorismo.

\subsection{LIDERANDO PROFISSIONAIS EMPREENDEDORES}

$\mathrm{Na}$ era do conhecimento, um dos principais desafios das organizações é atrair pessoas de talento. Hoje, praticamente todo executivo reconhece a importância de ter indivíduos de alta criatividade e capacidade de inovação na equipe. Mas apenas atrair talentos não basta. É preciso cultivar um ambiente favorável que inspire os profissionais a atingir todo seu potencial e que gere valor e riqueza para todas as partes interessadas no sucesso da organização (SILVA, 2003).

Dornelas (2005) afirma que o próprio Bill Gates sempre buscou os melhores programadores do mercado para desenvolver seus produtos, fator essencial para o sucesso da Microsoft. Esses profissionais da Microsoft e de tantas empresas de sucesso são os 
“executivos empreendedores". Pessoas brilhantes, criativas e inovadoras que constituem o recurso mais escasso e importante para as empresas do século XXI.

Os executivos empreendedores criam novos projetos, arriscam, revolucionam e fazem diferença no mundo dos negócios. Afinal, todos os recursos e sistemas do mundo são inúteis se não houver gente capacitada para gerenciá-los. Porém, é preciso que as organizações saibam liderar os "executivos empreendedores", se quiserem desenvolvêlos e aproveitar esse diferencial competitivo.

Algumas características comuns aos empreendedores podem tornar difíceis suas gestões e nem todo líder está capacitado para conduzi-los. Em primeiro lugar, um executivo empreendedor não gosta de receber ordens. $\mathrm{O}$ gestor que tentar levar o empreendedor a fazer algo que ele não concorde provocará sua saída da organização. Portanto, há um novo perfil de líder, alguém capaz de inspirar criatividade, algo muito diferente do gestor tradicional.

O novo líder precisa conhecer as características mais comuns do empreendedor. O empreendedor conhece seu valor, entende do negócio e da organização, ignora a hierarquia, é pouco resistente ao tédio e geralmente não mostra gratidão. Seu foco está nas atividades que realmente agregam valor e trazem resultado para a organização. $O$ empreendedor não tem interesse em processos burocráticos, metódicos, que não se traduzem em grande melhoria de performance.

Dornelas (2005) considera que é preciso compreender que esses profissionais são diferenciados e, por isso, querem ser tratados de forma diferenciada. Assim, o líder de executivos empreendedores deve ser um gestor benevolente e dar espaço para que o empreendedor possa se desenvolver na empresa. Bill Clinton, que dirige a London Business School, afirma-se que "é preciso ajudar os mais brilhantes a entender que sua inteligência não significa que podem fazer outras coisas. É bem possível que esse pessoal superestime o próprio domínio de outras áreas. Logo, o líder deve mostrar que tem competência para ajudar".

Uma vez estabelecida uma relação de respeito profissional, outro desafio do líder é estabelecer uma relação de confiança. $\mathrm{O}$ executivo empreendedor quer se sentir seguro para trabalhar de forma independente, sem perder a interdependência que tem com seu gestor e com a empresa. Isto só é possível num ambiente de credibilidade, onde é possível acreditar que suas ideias não serão utilizadas por outras pessoas e que seus conhecimentos em conjunto com o de outros indivíduos da organização proporcionarão resultados que 
não seriam alcançados se ele trabalhasse sozinho. Enfim, o líder capacitado para liderar executivos empreendedores proporcionará um ambiente favorável para o crescimento de uma empresa verdadeiramente inovadora.

\subsection{VANTAGEM COMPETITIVA: DIFERENCIANDO SUA EMPRESA, PRODUTOS E SERVIÇOS}

Drucker (2008) destaca que quase todas as pessoas querem ver, ou experimentar, todas as coisas das quais já ouviram falar. Vivemos em um contexto social extremamente consumista, numa nova realidade comercial. Mercados globais, produtos padronizados para venda em larga escala, numa grandeza jamais imaginada.

As corporações trabalham neste novo contexto para aproveitar os benefícios desta economia de escala na produção, na distribuição, no marketing e na gerência. Traduzindo estes benefícios para preços mais baixos em âmbito mundial, elas podem dizimar concorrentes que ainda vivem sob as amarras dos antigos paradigmas.

Dornelas (2005) considera que o desafio do novo empreendedor é tão desafiador quanto promissor. Competir num mercado globalizado de gigantes corporativos é uma árdua tarefa, mas o sucesso do empreendedor também pode viabilizar sua inclusão neste enorme mercado consumidor. $\mathrm{O}$ empreendedor precisa conscientizar-se que entrar num segmento de mercado é competir com gigantes, ou inovar e se tornar um pioneiro, assumindo todos os riscos que isto envolve.

Para Silva (2003), a dica então é a diferenciação. Uma empresa deve tentar diferenciar seus produtos e serviços para obter competitividade no mercado.

A diferenciação de produto começa em sua criação. Primeiro cria-se uma versão básica para o produto, que posteriormente pode ter versões adicionais ao acrescentar características extras. Por exemplo, a indústria automobilística desenvolve uma versão básica para um veículo e depois desenvolve assessórios para este veículo e oferece o produto com versões diferenciadas. Cada característica adicional tem a chance de atrair a simpatia de compradores adicionais.

Kotler (2012) considera que algumas empresas são muito inovadoras em acrescentar características para seus produtos. A indústria japonesa de câmeras fotográficas e relógios, por exemplo, promove uma constante evolução de tipos e modelos com opções bastante diferentes para atrair constantemente novos consumidores, uma maneira bastante eficaz de se competir nestes mercados.

REMIPE- Revista de Micro e Pequenas Empresas e Empreendedorismo da Fatec Osasco V. 3, N¹, jan.-jun. 2017. 
Como acertar nas características de seus produtos? Para responder a essa pergunta, é preciso fazer a pergunta certa a pessoa certa, ao seu cliente: Você gosta deste produto? Por que você gosta deste produto? Quais características deste produto são positivas? Quais características deste produto são negativas? Há características que poderiam ser acrescentadas? Quais são essas características? Quanto você pagaria por estas características?

Kaplan e Norton (2004) consideram que este tipo de pesquisa é o suporte para o desenvolvimento dos produtos. A tarefa seguinte é tabular os dados e optar pelas características que deverão ser aproveitadas ou não. Estes critérios são o ponto de partida para o desenvolvimento de produtos com foco no cliente. A análise deve pensar ainda em "pacotes" de características, no custo de produção, na viabilidade de implantação e outros.

Há também a diferenciação de serviços. Além de diferenciar seus produtos físicos, a empresa precisa diferenciar também os serviços que os acompanham. Especialmente quando o produto não pode ser facilmente diferenciado, a saída para conseguir vantagem competitiva está nos serviços que agregam valor aos produtos.

Para Silva (2003), o importante é desenvolver a cultura de inovação e criatividade na equipe para potencializar este importante conceito na realidade da organização. Logo, deriva destes conceitos um número ilimitado de serviços e benefícios específicos que podem ser oferecidos para diferenciar uma empresa de seus concorrentes.

\subsection{LIDERANÇA COMO FATOR DE DESENVOLVIMENTO DA EMPRESA}

Dornelas (2005) destaca que liderança é um termo que desperta "paixões" quando abordado em gerenciamento de negócios. Alguns profissionais atribuem um peso exagerado ao assunto, enquanto outros quase o ignoram, preferindo priorizar os processos como responsáveis pelo sucesso das empresas. De qualquer forma, o conceito está sempre presente nos treinamentos de capacitação gerencial, e, normalmente, ao se abordar liderança faz-se referência a uma pessoa, aquela que está à frente dos negócios e faz a diferença por meio da tomada de decisão.

Assim, segundo Silva (2003), o aprofundamento do conhecimento sobre liderança empresarial é uma forma fascinante de compreender fatores importantes que impactam as decisões estratégicas que acontecem no campo social das empresas, como 
padrões de conflito e disputa de poder, e como estas decisões afetam o desempenho corporativo.

Para Drucker (2008), talvez não exista um perfil padrão de liderança empresarial e nem seja possível ser líder sempre ou em qualquer empresa; mas é possível desenvolver habilidades e competências que potencializem o desempenho e aumentam as chances de capacitar verdadeiros líderes. A empresa, por outro lado, deve estimular este desenvolvimento. O exercício da liderança melhora a relação entre pessoas na empresa, construindo assim um melhor clima organizacional, aumentando o valor em capital humano, e melhorando muito suas chances de sucesso

\section{CONSIDERAÇÕES FINAIS}

O desenvolvimento da sua empresa não é um projeto, pois não tem início, nem meio e nem fim. É uma missão árdua e contínua. Ser empreendedor é possuir a habilidade de identificar boas oportunidades e negócios e ter a competência de transformar sonhos em realidade empresarial. Este desafio é tão fascinante quanto difícil, e o sucesso dos empreendedores sempre resulta de um histórico repleto de dificuldades e superações. Estamos na "Era do Empreendedorismo", e os empreendedores quebram barreiras sociais e culturais, renovam conceitos econômicos, quebram paradigmas e geram riquezas. $\mathrm{O}$ empreendedorismo é o melhor tipo de investimento, onde o retorno é muitas vezes de difícil mensuração. O sucesso do empreendedor está fundamentado em três pontos básicos: (1) o desafio que estimula as pessoas a lutarem por alguma coisa; (2) o resultado que dá a sensação de vitória e autoconfiança para continuar adiante e (3) a própria responsabilidade de comemorar as vitórias e corrigir os erros cometidos.

Quanto aos estudos realizados sobre os traços de personalidade dos empreendedores demonstram resultados variados, sem levar em consideração as habilidades e competências desenvolvidas ao longo de sua trajetória profissional.

Assim, entendemos que, ao invés de focar nos atributos de personalidade, é preciso analisar as habilidades e competências necessárias para o sucesso do empreendedor. Habilidades e Competências podem ser desenvolvidas, adquiridas, ou, pelo menos, melhoradas ao longo da carreira profissional, de forma a ajudá-los a serem bem-sucedidos.

O bom planejamento prévio do negócio é fator indispensável para o seu sucesso. Dessa forma, é preciso criar uma cultura organizacional favorável ao desenvolvimento da 
empresa. O bom clima organizacional estimula o trabalho em equipe, a criatividade e a inovação, fatores indispensáveis para competitividade no mundo dos negócios. Os líderes e os profissionais empreendedores desenvolvem os produtos, serviços e negócios que a empresa comercializará futuramente, para buscar garantir o crescimento e a sustentabilidade institucional

\section{REFERÊNCIAS}

BIRLEY, Sue; MUZYKA, Daniel F. Dominando os Desafios do Empreendedor, São Paulo: Pearson Education do Brasil, 2004.

CAPUCHA, L. Promoção do Empreendedorismo na Escola. Editorial. In PEREIRA, M. M., FERREIRA, J. S.; FIGUEIREDO, I. O. Guião Promoção do Empreendedorismo na Escola (p. 5-6). Lisboa: Ministério da Educação / Direcção-Geral de Inovação e Desenvolvimento Curricular, 2007.

DOLABELA, Fernando. Oficina do Empreendedor. São Paulo: Editora Cultura, 2008.

DORNELAS, José Carlos Assis. Empreendedorismo corporativo: como ser empreendedor, inovar e se diferenciar em organizações estabelecidas. Rio de Janeiro: Elsevier, 2005.

DRUCKER, Peter F. Inovação e espírito empreendedor: Prática e princípios. São Paulo, 2008.

GEM. Relatório Executivo do Global Entrepreneurship Monitor. 2013. Disponível em: $<$ http://www.sebrae.com.br/Sebrae/Portal\%20Sebrae/Anexos/GEM_2013_Pesquisa _Completa.pdf.> Acesso em: 6 mar. 2015.

HERMANSON, Boris. O que é uma startup? São Paulo: Mundo Sebrae,2011. Disponível em: <http://www.mundosebrae.com.br/2011/01/o-que-e-uma-startup/> Acessado em 27/08/2015 às 21:03.

KAPLAN, Robert S.; NORTON, David P. A Estratégia em Ação - Balanced Scorecard. 9.ed. Rio de Janeiro: Elsevier, 2004.

KOTLER, Philip. Administração de Marketing: a edição do novo milênio. São Paulo: Prentice Hall, 2012.

LONGHI, Fúlvio. A história da revolução das startups. Imasters,2011. Disponível em: http://imasters.com.br/artigo/20027/mercado/a-historia-da-revolucao-dasstartups.

Acessado em: 27/08/2015 às 20:29.

MCCLELLAND, David. The Achieving society. New York:D:VanNostrand,1961.

OSTERWALDER, Alexander. Business Model Generation -Inovação Em Modelos de Negócios. São Paulo. Alta Books, 2011.

REMIPE- Revista de Micro e Pequenas Empresas e Empreendedorismo da Fatec Osasco V. 3, N¹, jan.-jun. 2017. 
SEBRAE, 2013. Disponível em http://www.sebrae.com.br/uf/paraiba/o-que-eumaempresa-startup/o-que-e-uma-empresa-startup. Acessado em 20/08/2015.

SEBRAE - Serviço de Apoio às Micro e Pequenas Empresas de Santa Catarina. Como abrir e fazer a gestão de uma clínica odontológica. Conselho Regional de Odontologia de Santa Catarina, 2014. Disponível em: <http://www.sebrae.com.br/ Sebrae/Cartilha_Odontologia_Sebrae_SC_26_Ago_2014.pdf $>$. Acesso em: 19 jun. 2014.

SILVA, L. C. O Balanced Scorecard e o processo estratégico. Caderno de Pesquisas em Administração. v. 10, n. 4, 2003, p. 61-73. 